\title{
Mais Tutoria sem Aglomeração de Pessoas: Em tempos de COVID-19
}

\section{More Mentoring without People Agglomeration: In Times of COVID-19}

\author{
José Valdeni DE LIMA \\ Universidade Federal do Rio Grande do Sul (UFRGS) \\ Centro Interdisciplinar em Novas Tecnologias na Educação (CINTED) \\ Instituto de Informática (INF) \\ Programa de Pós-Graduação em Informática na Educação (PPGIE)
}

\begin{abstract}
Resumo: A atividade de Tutoria é o esforço que o tutor (frequentemente o próprio professor) deve fazer para acompanhar cada aluno de forma personalizada colocando à disposição de cada aluno os conteúdos significativos (Ausubel) na dosagem sob medida (Bloom's 2 Sigma Problem) para que 0 aluno possa fazer suas práticas pedagógicas e assim melhorar sua aprendizagem. Quanto mais personalizado for este acompanhamento (relação um tutor - um aluno), mais o tutor conhece o aluno, permitindo autenticar se é o próprio aluno que está fazendo suas atividades, em vez dele repassar ou copiar de um outro. O contato face a face, relação 1 professor/tutor 1 aluno, em sua maioria ocorrendo atualmente de modo virtual, quando presencial, será organizado com os devidos cuidados para o bom isolamento social.
\end{abstract}

Palavras-chave: Tutoria, Aprendizagem Significativa, Competência de Dosagem, 2 Sigma Problem.

\begin{abstract}
The Mentoring activity is the effort that the Tutor (frequently the Teacher) must make to accompany each student in a personalized way, placing at their disposal significant contents (Ausubel) and in the customized dosage (Bloom's 2 Sigma Problem) that they can practice to improve learning. The more personalized this accompaniment (the relationship of a tutor and a student) the better the teacher knows the student and makes sure that it is the student him or herself who is doing the activities instead of passing them on or copying them from another student. Face-to-face contact, mostly virtual nowadays, when in person, will be organized with due care for good social isolation.
\end{abstract}

Keywords: Mentoring, Significative Learning, Competence of dosage, 2 Sigma Problem. 


\section{Introdução}

Pela primeira vez, minhas 2 (duas) disciplinas estão sendo lecionadas na modalidade $100 \%$ a distância, com as anuências de todos os alunos, o que está permitindo vivenciar uma experiência real de educação on-line entre os participantes (alunos e professores). Boa parte das pessoas está em teletrabalho (Home Office) para não parar, principalmente quem atua na Educação e na Pesquisa. Nunca o mundo esteve tão preparado para educar as pessoas na modalidade EaD (Educação a Distância) evitando aglomeração de alunos e professores, o que diminui o contato face a face presencial, mas permite este contato através das TICs (Tecnologias de Informação e Comunicação) disponíveis.

Muitas vezes, o Professor move montanhas para poder ensinar. Também, o Aluno que quer aprender precisa vencer muitos obstáculos. Não são poucos os exemplos neste Brasil de professores e alunos que caminham quilômetros diariamente por falta de transporte público, sem acesso às TICs, sem acesso à Internet, sem tempo para se dedicar (pois o professor precisa ter mais de um emprego para poder sobreviver e o aluno um emprego para poder comer), sem acesso a qualquer suporte de Tutoria em meio a outros tantos obstáculos para que o processo ensino-aprendizagem seja possível. Se professores e alunos se unirem e se motivarem, não serão vírus nem burocracias que os impedirão de melhorar o processo ensino-aprendizagem na modalidade EaD.

O suporte de Tutoria a que me refiro no parágrafo anterior é o esforço que o Tutor/Professor deve fazer para acompanhar cada aluno de forma personalizada, colocando à sua disposição conteúdos e recursos significativos (Ausubel) na dosagem sob medida para que ele possa praticar (práticas pedagógicas) e assim melhorar a sua própria aprendizagem. Quanto mais personalizado é este acompanhamento, melhor o tutor/professor conhece seu aluno e mais capacitado é para se certificar de que é o próprio aluno que está fazendo suas atividades e não pedindo para que um outro as faça em seu lugar. Entre as 3 (três) relações possíveis [7], a saber: (i) 1 tutor - 1 aluno; (ii) 1 tutor - vários alunos; e (iii) vários tutores - vários alunos, a primeira relação é a mais personalizada. Como é impossível economicamente ter 1 tutor para cada aluno no Brasil, as TICs disponíveis podem ajudar a viabilizar esta personalização. Exemplos de tecnologias que permitem um diálogo mais personalizado entre tutor e aluno são os robôs virtuais que tiram dúvidas [6] e os Sistemas de Recomendação $[1,3]$.

\section{Competência de Dosagem}

Existem dois ditados populares que fazem referência à mesma competência de dosagem: "A diferença entre o remédio e o veneno está na dose" e "Tudo demais é veneno". Até água, que é vital para o ser humano, pode ser mortal se ingerida em grande quantidade. Bem, neste presente texto, a chamada "Competência de Dosagem" é a capacidade de saber dosar a quantidade das atividades ao tempo disponível do aluno. Esta competência de dosagem é fundamental para os alunos que finalizam o Ensino Médio, caso contrário eles não sobreviverão no ambiente 
universitário e não saberão gerenciar a sobrecarga cognitiva a que estarão submetidos. Às vezes, a Competência de Dosagem é confundida com Autonomia. A Competência de Dosagem, que vem antes da Autonomia, é a capacidade do aluno escolher, no excesso de atividades, aquelas que são relevantes para que consiga dosar a prática pedagógica ao seu tempo disponível. É claro que a Autonomia não é simplesmente fazer todas as atividades que todos os professores passam quando o aluno entra na faculdade, pois não há tempo disponível e cada professor acha que sua disciplina é a mais importante. Não existe um interesse de um esforço coletivo de razoabilidade de dosagem das atividades das disciplinas de um semestre, por exemplo. Isto é uma das razões de tantas desistências e solicitações de transferências de cursos de bons alunos que eram cumpridores de todos os seus deveres de casa durante o Ensino Fundamental. Existe um ditado popular francês: "À I'impossible nul nest tenu". A moral do referido ditado é que ninguém é obrigado a realizar uma tarefa que não é possível de ser realizada.

O Brasil tem uma grande experiência em EaD, pois desde 1941 existem Cursos oferecidos nesta modalidade. Por exemplo, o Instituto Universal Brasileiro (www.institutouniversal.com.br) oferece Cursos profissionalizantes, técnicos e supletivos de nível médio e fundamental há muito tempo. Os famosos Cursos por Correspondência (Os Correios e Telégrafos era a tecnologia) já eram na modalidade EaD. A Inglaterra foi um dos primeiros países que ofereceram cursos na modalidade EaD como uma porta de ascensão social, reforçando a democracia (todos as pessoas têm a oportunidade de ter uma Educação independentemente de sua posição social). No Brasil, passar no Vestibular (agora, ser aprovado no ENEM) é uma porta que se abre como oportunidade de um futuro melhor. Ter também um exame nacional do ensino fundamental, o Exame Nacional do Ensino Fundamental (ENEF), poderia ser útil para a avaliação e medidas para melhorar o Ensino Fundamental e, como consequência, a Educação Brasileira.

É um erro uma sociedade não tomar os devidos cuidados para proteger nossos jovens para não entrar no mundo da ilegalidade e priorizar como formas de ascensão social "ganhar na loteria" ou "ser jogador de futebol", em vez da Educação.

Vários pesquisadores da área Interdisciplinar da Informática na Educação sabem que o "Bloom 's 2 Sigma Problem" do psicólogo Benjamin Bloom [1] pode ser quase solucionado com as TICs disponíveis $[2,4,7,8]$. Ou seja, nenhum Processo Ensino-Aprendizagem é mais eficiente do que na relação 1 Professor/Tutor - 1 aluno (um professor/tutor que saiba a matéria, queira ensinar e queira acompanhar de forma personalizada a aprendizagem de seu aluno que, por sua vez, queira aprender). E o melhor de tudo isto é que é mínimo o contato face a face (vis-à-vis do francês e face to face do inglês) neste processo ensino-aprendizagem, o que evita não apenas a aglomeração de pessoas, mas, também, contribui para o isolamento social. É verdade que seria necessário muitos mais professores para que esta Tutoria (acompanhamento personalizado de cada aluno) fosse possível, devido à grande carga de trabalho exigida de cada professor/tutor. O modelo de escola que se conhece dá acesso à Educação a um maior número de pessoas sem ter que contratar inúmeros professores/tutores, mas, como efeito colateral, acarreta a 
aglomeração de pessoas. Também, tenta corrigir uma das maiores consequências da desigualdade (fome), através da alimentação de crianças carentes.

\section{Competências Desejáveis dos Alunos}

As competências desejáveis no final do Ensino Fundamental, em ordem de importância, segundo o autor deste ponto de vista, são: (i) Domínio das tecnologias atuais, (ii) domínio de sua língua materna (no nosso caso o português), (iii) aplicabilidade de conceitos matemáticos e estatísticos, e (iv) convivência social. Porque se coloca o domínio das tecnologias atuais como sendo mais importante que o domínio da língua materna (em termos de escrita, pois a oralidade é imprescindível [5]). A resposta para esta pergunta pode ser captada através de algumas oportunidades que surgem. Por exemplo, alguns projetos internacionais de que participo com a França aceitam receber alunos para trabalhar em seus laboratórios sem que o aluno fale bem o francês, mas fale um inglês compreensível e domine a tecnologia que estamos pesquisando. Também, pode ser constatada a inclusão no mercado de trabalho de pessoas analfabetas que se comunicam com seu empregador por mensagem de voz através de seu celular. Por exemplo, a cuidadora de minha mãe é analfabeta, não escreve nem lê, mas faz razoavelmente seu trabalho se comunicando com os familiares por mensagens de voz. Ou seja, a tecnologia facilitou tanto a Interface de aplicativos que, com simples cliques (apontar e clicar ou tocar), qualquer pessoa consegue ter acesso.

Embora a Competência de Dosagem seja fundamental para o aluno que ingressa em um curso universitário, é desejável que ele já tenha conhecimento de outras culturas e de uma outra língua.

Finalmente, a motivação constitui outro aspecto chave para o sucesso do Processo EnsinoAprendizagem. Mas, não se pode criar dificuldades que a destruam, tais como conteúdos ministrados sem os devidos ancoramentos nos subsunçores do aluno, ausência de dosagem sob medida do conteúdo (evitar sobrecarga cognitiva e sensação de não realização das atividades), falta de domínio das TICs disponíveis [4,7], entre outras, que costumam implicar perda de motivação. Portanto, as Trajetórias de Aprendizagem precisam ser bem planejadas, bem executadas e bem avaliadas, em um círculo virtuoso que efetivamente melhore o Processo Ensino-Aprendizagem.

\section{Agradecimentos}

Agradeço as contribuições dos Professores Doutores Leandro Krug Wives, Valter Roesler, José Palazzo Moreira de Oliveira, Raquel Salcedo Gomes, Alberto Basto do Canto Filho e outros membros do Grupo TRAPHU (Trajetórias de Aprendizagem em Hiperdocumentos Ubíquos), através de nossas reuniões mensais.

Agradeço também à agência do governo CAPES (Coordenação de Aperfeiçoamento de Pessoal de Nível Superior) pelo suporte financeiro ao Programa de Pós-Graduação em Informática na Educação, inclusive apoiando com passagens para dois Sanduíches de Doutorado nos EUA, 
envolvendo o desenvolvimento do aplicativo CareTaker ${ }$, com nossa parceira Profa. Dra. Simone

Conceição da School of Education da UWM (University of Wisconsin-Milwaukee).

\section{Referências}

1. BLOOM, B. S. et al. Taxonomy of educational objectives. New York: David Mckay, 1956. 262 p. (v. 1).

2. KAMPFF, A. J. C.; REATEGUI, E. B. and LIMA, J. V. Mineração de dados educacionais para a construção de alertas em ambientes virtuais de aprendizagem como apoio à prática docente. RENOTE. Revista Novas Tecnologias na Educação, v. 6, p. 3, 2008.

3. KNOWLES, BRAN et al.: Uncertainty in Current and Future Health Wearables. In. Communications of the ACM 61 (12), 62-67. (December 2018).

4. KUHN, I.; ROCHA, P. S.; DE LIMA, JOSE VALDENI; WIVES, L. K.; GOMES, R. S.; JARDIM, R. R. Análise de desempenho de estudantes utilizando técnicas de agrupamento com mineração aplicado a curso de pós-graduação à distância. In: Challenges 2019: Desafios da Inteligência Artificial - XI Conferência Internacional de TICs, 2019, Braga - Portugal. Challenges 2019: Desafios da Inteligência Artificial - XI Conferência Internacional de TICs. Braga: Universidade do Minho, 2019. v. Único. p. 1113-1124. Os Desafios para Superação das Barreiras Atitudinais na Educação Escolar: Estudo de Caso com Alunos de um Colégio Público

5. MCLUHAN, M. A galáxia de Gutenberg; a formação do homem tipográfico; tradução de Leônidas Gontijo de Carvalho e Anísio Teixeira. São Paulo, Editora Nacional, Editora da USP, 1972. 390p

6. MELO, J. N. B.; DE LIMA, J. V. and CARDOSO, E. In book: Informática na Educação: Recursos de Acessibilidade da Comunicação, Publisher: EDITORA UFRGS (December 2019).

7. PEREIRA, D. S.; LIMA, J. V.; JARDIM, R. R.; ROCHA, P. S.; SANTOS, F. E.; TAROUCO, L. M. R. . HTML5 Authoring Tool to Support the Teaching-Learning Process: a case study with H5P framework. INTERNATIONAL JOURNAL FOR INNOVATION EDUCATION AND RESEARCH, v. 7, p. 92-103, 2019.

8. PINHEIRO, M. K.; LIMA, J. V. and BORGES, M. R. S. A Framework for Awareness Support in Groupware Systems. Computers in Industry, v. 52, p. 47-57, 2003.

Recebido em maio de 2020.

Aprovado para publicação em maio de 2020.

\section{José Valdeni DE LIMA}

Programa de Pós-Graduação em Informática da Educação (PPGIE), Centro Interdisciplinar em Novas Tecnologias na Educação (CINTED), Instituto de Informática (INF) - Universidade Federal do Rio Grande do Sul (UFRGS), Brasil, valdeni@inf.ufrgs.br 